\title{
Molecular Profile of Human Serine Palmitoyltransferase-1 Proximate of Chromosome 9 Disease Susceptibility Gene Cluster in Inflammatory Cancer Cell Lines
}

\author{
Tokunbo Yerokun*, Tamra Neblett, Chénel Johnson \\ Biology Department, Spelman College, Atlanta, Georgia, USA \\ Email: tyerokun@spelman.edu
}

Received 21 June 2014; revised 20 July 2014; accepted 15 August 2014

Copyright (C 2014 by authors and Scientific Research Publishing Inc.

This work is licensed under the Creative Commons Attribution International License (CC BY).

http://creativecommons.org/licenses/by/4.0/

(c) (i)

Open Access

\begin{abstract}
Background: Over 1100 genes have been annotated for human chromosome 9, including disease genes implicated in inflammation, atherosclerosis, cancer and neurodegeneration. The serine palmitoyltransferase-1, SPTLC1, gene is at the 9q22.2 cytogenetic band, a high G+C content region with common genetic alterations sufficient to modify cellular behavior. The sequence is highly conserved among diverse species from bacteria to humans, including a recently discovered 126 nucleotide alternate open reading frame, AltORF. The protein encoded by the reading frames has domains of biological interest and considerable overlapping molecular functions associated with cellular behavior and cancer progression. Methods: Here we examined molecular features of SPTLC1 in a group of inflammation associated cancer cell lines SKN-SH, MDA-PCa, Glioma LN18, PC3 and 647V. Subcellular localization of SPTLC1 was assessed by immunofluorescence microscopy and recombinant green fluorescent protein expression. In addition, PCR, DNA sequencing and bioinformatics analysis were used for molecular profiling of the SPTLC1 genomic and reverse transcribed cDNA fragments. Results: SPTLC1 is detected in all cell lines examined, with intense peri-nuclear staining, consistent with localization in the cytoplasm. Genomic DNA sample, but not the cD NA of SKN cells could be amplified with an AltORF primer set. The PC3 and MDA-PCa cancer cell lines which are both of prostate origin, show differences in SPTLC1 PCR amplification. Similar levels of SPTLC1 AltORF transcripts were detected by quantitative RT-PCR in all cell lines, except the PC3 cell line with low transcript level whose cDNA did not generate nucleotide base sequence information. Conclusions: This is the first reported transcriptional expression of the SPTLC1 AltORF for the inflammation associated human cancer cell lines. Interestingly, it is proximate of on-
\end{abstract}

${ }^{*}$ Corresponding author.

How to cite this paper: Yerokun, T., Neblett, T. and Johnson, C. (2014) Molecular Profile of Human Serine Palmitoyltransferase-1 Proximate of Chromosome 9 Disease Susceptibility Gene Cluster in Inflammatory Cancer Cell Lines. Journal of Cancer Therapy, 5, 885-901. http://dx.doi.org/10.4236/jct.2014.510096 
cogenic cancer susceptibility genes and distal of tumor suppressor genes, the high content of short nucleotide repeats in the SPTLC1 AltORF sequence suggesting the region may be genetically unstable. This nominal functional genomics report on the human SPTLC1 AltORF will contribute to compiling a more detailed SPTLC1 gene ontology and is expected to help shed more insight into unique molecular attributes of SPTLC1 in the context of cancer cell behavior, malignant progression and the design of treatment for inflammation associated cancers.

\section{Keywords}

\section{Cytogenetic Band, Functional Genomics, Human Chromosome 9, Microsatellite Instability, Serine Palmitoyltransferase-1}

\section{Introduction}

\subsection{SPTLC1 Has Non-Enzymatic Function}

Molecular perturbation of the human SPTLC1 gene and regions proximate of its locus on chromosome 9 is linked to altered cellular processes, drug response and human disorders. The molecular mechanisms by which SPTLC1 may contribute to these processes remain to be fully determined. The expression of the SPTLC1 protein is reported to be enhanced in normal proliferating cells, such as the lung, stomach and intestinal epithelium and in stromal fibroblasts surrounding malignant epithelial tissues [1] [2]. More recently, confocal microscopy has localized SPTLC1 at the leading edge of cells in an in vitro model of wound healing [3]. Mutations in the SPTLC1 gene have been linked to hereditary sensory neuropathy type 1, HSN1 [4]-[7]. Symptoms associated with the disease include, in some cases, altered sphingolipid biosynthesis, which is thought to be due to catalytic promiscuity that results in the synthesis of toxic derivatives [8] [9]. Often seen in neurodegenerative diseases [10], the resulting toxic micro-environment can lead to neural cell death and the late-onset neurodegeneration associated with the disease [11]. However the link between perturbing the SPTLC1 gene and altered composition of bioactive derivatives generated in the metabolic pathway has been tenuous. It is conceivable from accumulating evidence that the complexity of cellular responses which accompany the perturbation of SPTLC1 expression [12], derives from factors other than changes in cellular composition of bioactive and toxic sphingolipids alone. Knowledge of SPTLC1 molecular biology has rapidly progressed since the determination of its DNA sequence [13], allowing advances to be made in its sub-cellular localization, particularly stress-induced translocation to sites of focal contacts in mammalian cells [3] [14], as well as, identifying novel functional characteristics of SPTLC1. It is now possible to design studies for the predictive understanding of the precise consequences that the perturbation of SPTLC1 expression has on cellular processes.

Although a direct cancer association has not been established for SPTLC1, regions distant and proximate to the gene are known cancer disease loci. Several chromosome 9 aberrations such as mutations, chromosomal deletion, translocation events or epigenetic alterations are found associated with progression of the cancer process. A number of SPTLC1 binding partners encoded by genes on the human chromosome 9q and functionally linked to the regulation of multiple biological processes have been identified using antibody-mediated "pull down" approaches. These binding partners have functional diversity, suggesting that SPTLC1 may contribute in regulating biologic processes through dynamic protein-protein interactions. The availability of bioinformatics analysis tools for annotating the human genome has further opened the door for the identification of protein-protein interaction motifs and the functional relevance of these motifs for the discovery of an increasing number of SPTLC1 binding partners. As extensive knowledge of the biochemistry of SPT and increasing understanding of the molecular biology of SPTLC1 converge, it has become necessary to redefine SPTLC1 function in terms of non-enzymatic contribution to regulating important aspects of cell physiology, cell growth, inflammation, drug response, as well as, stress response mechanisms important to human health.

\subsection{Human SPTLC1 Gene Encoded Structure and Functional Domains}

Annotation of the human SPTLC1 gene allows deriving information on gene architecture, regulatory sequences, functional domains, protein-protein interactions, as well as, predict novel molecular mechanisms of action. The 
SPTLC1 gene has been mapped to chromosome 9q22.2/22.31 cytogenetic band region [15], a chromosome with over 1100 other genes. Some of chromosome 9 alterations have become a hallmark of carcinomas where mutations, deletion events and epigenetic alterations are linked to the process of tumor formation and progression [16]. Homology searches of the human genome sequence show that the published SPTLC1 open reading frame (ORF) encodes a protein with several obvious and significant motifs that predict interaction with diverse protein moieties and, depending on its temporal-spatial expression, crosstalk with proteins in signaling networks regulating normal physiology and disease states. Some of these domains illustrated in Figure 1, highlight some of those that may allow protein-protein interactions for crosstalk in stress response signaling. Its PDZ domain can scaffold it with a variety of other proteins in specific regions of the cell, such as focal adhesion sites. It has sequences which match Src homology-2, -3 (SH2, SH3) protein-protein binding domains including YLEK, YKLQ, YCFS, QPEPLVP and YNIVSGP, that, presumably, could target SPTLC1 to membrane domains and proteins [17], plus a DLERLLK sequence for nuclear localization. The SH3 binding domain can be used for binding to proline rich sequence in target protein partners such as paxillin. The C-terminal region of SPTLC1 has phosphorylation sites that allow crosstalk with structural or signaling proteins [18] regulating cellular morphology, growth and viability.

A recent gene discovery study has identified an SPTLC1 alternate open reading frame (AltORF) in the C-terminal region of its genome. The out-of-frame alternative translation initiation in human mRNAs [19] [20] is thought to contribute to the functional diversity of the human proteome [21], but this remains to be determined for the SPTLC1 AltORF. The SPTLC1 ORF encodes a long chain base fragment in the +3 reading frame while the SPTLC1 AltORF is aligned with the ORF at nucleotides 1585 to 1710 , in the +1 reading frame. The SPTLC1 ORF encodes a 473 amino acids protein of at least a highly conserved 53 kiloDalton (kD) sub-unit, while the AltORF encodes a 41 amino acids peptide [22]. The structure of the long chain protein is now best appreciated as that of a dynamic fragment capable of interacting with multiple partners including, SPTLC2 and SPTLC3 in the catalytic heterocomplex [23], as well as, in other signaling modules involved in the regulation of diverse cellular processes [3] [14]. Amino acids at the highly conserved C-terminus of SPTLC1 conform to a type II PDZ protein interaction motif known to play an important role in the assembly of signal complexes. Mutation at the extreme carboxyl-terminal region of SPTLC1 which lead to disruption of heterodimer formation not only confirmed a role for SPTLC1 in heterodimer formation and membrane tethering, but also the potential to bind multiple proteins in diverse signaling pathways. Implicating additional functional roles for SPTLC1 are its observed interaction with transport, structural and signaling proteins in cellular pathways of cell proliferation and death [3] [14] [24]. Bioinformatics analysis and protein structure modeling of the SPTLC1 AltORF predicts a fragment with nuclear localization signal (NLS) sequence KKKTH, cAMP- and cGMP-dependent protein kinase phosphorylation sites KKKT and a protein kinase C phosphorylation sites, including ALS and TMR. In general, the features of SPTLC1 identified in this report using bioinformatics analysis tools such as the ELM Resource, highlight evolutionarily conserved domains that predict putative role, either directly or indirectly, in diverse processes that range from the formation of a catalytic heterocomplex to modulating cellular signaling, transcriptional expression of gene and ultimately, cellular behavior.

\subsection{SPTLC1 Stress Response Binding Partners}

Various environmental stress stimuli, such as nutrient restriction, heat, chemotoxins and oxygenation, activate a

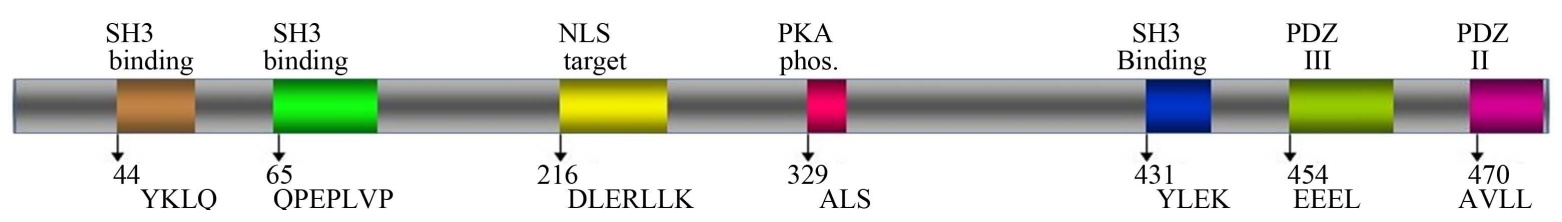

Figure 1. Mapping Functional Domains of Human SPTLC1. The map illustrates the full length SPTLC1 ORF fragment with some of the functional domains, in colors, that allow protein-protein interaction and phosphorylation of SPTLC1, which may be relevant to its role in stress response signaling. The top labels indicate binding targets; SH is SRC homology domain; NLS is nuclear targeting sequence; PKA is phosphokinase A phosphorylating sequence; PDZ is acronym combining the first letters of the three proteins for post synaptic density protein (PSD95), drosophila disc large tumor suppressor (Dlg1), and zonula occludens-1 protein (zo-1). The location and amino acid sequence for each functional domain are indicated at bottom of the map. 
range of cellular stress response pathways that lead to altered metabolic and proliferative status, which favors the survival of cancer cells and their progression to metastasis [25]. The reported translocation of SPTLC1 to focal adhesion sites [3] [14] [24], is to a sub-cellular domain that plays a critical role in a variety of cellular pathways and processes, including cell proliferation, morphology, and cell survival. SPTLC1 has also been coimmunoprecipitated with proteins of particular interest to cellular stress response such as the $90 \mathrm{kD}$ heat shock protein (Hsp90), a molecular chaperone and vinculin which is an F-actin-anchoring cytoskeletal protein [3] [14] [26]. Using immunoprecipitation-high throughput Mass Spectrometry (IP-HTMS), bait and prey gene assay, SPTLC1 is found to bind the Regulator of G-protein signaling protein, RGS20 [27], a protein that can act as a scaffold for organizing receptors, G-proteins or their effectors to enhance efficiency and specificity of signaling interactions [28]. Such interaction is reported to promote the metastasis of human melanomas [29], but it is not known whether SPTLC1 binding modulates the functions of RGS20. The SPTLC1 protein interacts with the evolutionarily conserved Pulmonary Adenoma Resistance 3 (Par3) cell polarity protein [30]. The Par3 protein acts as a scaffold-like PDZ-containing protein and plays a critical role in the formation of junctional complexes, establishing and maintaining polarity for epithelial cells. A novel protein-protein interaction between SPTLC1 and the third PDZ domain of Par3 has been reported from an immunoprecipitation study [30]. Similar to SPTLC1, in mice, disruption of the Par3 gene is embryonic lethal, causing aberrant development of epithelia [31] [32], suggesting the interaction may be important for cell-cell interaction, proper organization of epithelial tissues, as well as, cellular chemotaxis toward inflammatory signals. Members of the ATP-binding cassette (ABC) transporter family are primary active transporters, playing significant roles in absorption, metabolism and toxicity of pharmacological agents. ABCA1 plays an important role in cholesterol homeostasis and its efflux activity is central to cholesterol homoeostasis in diverse cells [24] [33]. Immunoprecipitation and Western analysis of cultured cell lysate indicate physical interaction between ABCA1 and SPTLC1 [24]. Mutation in chromosome 9q31 results is associated with defective ABCA1 transporter that lead to the inhibition of effective transport of cholesterol and phospholipids out of cells for pickup by ApoA1 in the bloodstream. The disruption of lipid metabolism and transport is implicated in cardiovascular, Alzheimer, Huntington, multiple sclerosis and diabetic diseases. Another member of the transporter family, ABCA2 is at 9q34, it belongs to the multidrug resistance/Transporter 1 (MDR/TAP) subfamily known to be involved in the acquisition of the multidrug resistance phenotype [34]. By interacting with either of the ABC proteins, there is the potential for SPTLC1 to be involved, in a non-catalytic role, in the progression of diverse human diseases.

\subsection{Putative SPTLC1-Chromosome 9 Linkage Group in Cancer Progression}

Proximate and distant genetic lesions on sections of chromosome 9, such as loss of heterozygosity (LOH), copy number variation and mutations are linked to molecular pathways for the formation and/or progression of glioblastoma, urothelial, prostate and other carcinomas [35] [36]. Genome wide association studies have detected a significant risk between single nucleotide polymorphisms in the 9q22 region and thyroid cancer susceptibility [37] [38]. An association of 9q31.2-rs865686 with breast cancer risk has been reported among women of European ancestry [39], as well as with 9q22.33 in other breast cancer patients [40]. Colorectal cancer, ovarian cancer, transitional cell carcinomas of the bladder, glioblastoma and neuroblastoma are other cancer diseases in which genetic lesion at the 9q region is implicated [41]-[43]. Bioinformatics analysis has been used in the present study to identify some members of a putative chromosome 9 functional linkage group encoding proteins that play roles in a wide spectrum of biological activities, including stimulation of cell growth, prevention of apoptosis, regulation of actin cytoskeleton, modulation of cell shape, cell migration and invasion [44]. The ABCA1 and ABCA2 proteins are involved in cholesterol transport and multidrug resistance, respectively. The endothelial differentiation gene 3 (Edg3) is a specific receptor for the sphingosine-1-phosphate (S1P) bioactive sphingolipid. The prostate cancer antigen 3 (PCA3 or DD3) is a prostate-specific non-protein coding sequence highly over-expressed in Prostate Cancer specimens [45] [46]. The Human Patch 1 (PTCH1) gene encodes a member of the patched gene family, a cytoplasmic receptor for a number of hedgehog proteins implicated in tumorigenesis [41]. Transforming growth factor, beta receptor 1, TGFBR1, is a serine/threonine protein kinase whose gene mutations have been associated with cancer risk [47]. The Abelson murine leukemia-1 (ABL1) protein is a non-receptor tyrosine-protein kinase that plays a role in cell growth and survival. Its chromosomal translocation can result in the breakpoint cluster region (BCR)/ABL1 fusion gene chimera a cytogenetic hallmark of chronic myeloid leukemia (CML) in which the fusion protein drives neoplasm [48]. Genetic and epige- 
netic changes in chromosome 9 regions remote to SPTLC1 have also been linked to urothelial cell carcinoma (UCC), the second most common genitourinary malignant disease in the USA and the heterogeneous Glioblastoma brain tumor [16], in which the cell cycle regulating cyclin-dependent kinase inhibitor CDKN2A/B gene at 9p21 is implicated. Genome-wide association studies of breast cancer have also linked the CDKN2A/B site as a susceptibility locus in Breast Cancer 1 (BRCA1) breast cancer patients [49] [50]. Taken together, the emerging biological roles for SPTLC1 in cancer biology suggest that they may be driven, in part, by the presence of motifs in the gene sequence that predict interaction with diverse protein moieties, its temporal-spatial localization and the capacity for crosstalk with proteins in signaling networks regulating biological processes. In this report, SPTLC1 is localized to cytoplasm of cancer cells of different tissue origin, all the cell lines examined have similar molecular profile based on PCR amplification of the gene transcript. DNA sequence analysis has been used to confirm a region with high nucleotide tandem repeat in the SPTLC1 AltORF that may be susceptible to genomic instability.

\section{Materials and Methods}

\subsection{Cells and Cell Culture}

All cell lines except 647V used in this study were purchased from American Type Culture Collection, Manassas, VA. Recombinant cells were generated by transfection with Lipofectamine (Life Technologies). Cells were grown in Dulbecco's modified Eagle's medium (DMEM), supplemented with $10 \%$ fetal bovine serum (FBS) and $100 \mathrm{U} / \mathrm{ml}$ penicillin and $100 \mu \mathrm{g} / \mathrm{ml}$ streptomycin and grown at $37^{\circ} \mathrm{C}$ in a humidified atmosphere of $5 \% \mathrm{CO}_{2}$. Cells were plated overnight at $3 \times 10^{4}$ cells per well of a 4-well chamber slide (Nalge Nunc, VWR, West Chester, PA), when stained for confocal imaging. All cell lines used here grow attached with epithelial morphology, except MDA PCa cells that grow minimally attached, as aggregates on culture vessels.

\subsection{Confocal Fluorescence Microscopy}

As previously described [14], cells were fixed with $3 \%$ paraformaldehyde in phosphate-buffered saline (PBS) for 15 min. After three washes with PBS, cells were permeabilized with $0.1 \%$ Saponin in PBS, soaked in blocking solution (1\% bovine serum albumin in PBS) then incubated for $1 \mathrm{hr}$ with primary antibody against SPTLCI (BD Biosciences) at a 1:500 fold-dilution. After 2 washes an Alexa-fluor 488-conjugated secondary antibody (Invitrogen) at 1:1000 fold-dilution was used for signal amplification. Hoescht 33,364 was used for nuclei staining and Phalloidin 596 (Invitrogen) at 1:1000 fold-dilution was used for F-actin cytoskeleton tagging. Stained cells were mounted with coverslip and examined using the Zeiss LSB 700 confocal microscope (Carl Zeiss, Germany), or the EVOS Fluorescence Microscope (Life Technologies Co.).

\subsection{SPTLC1 Recombinant Cells}

Recombinant vectors carrying full length, mutated or GFP chimera variants of the human SPTLC1 were generated as Custom DNA Oligos (Life Technologies, Grand Island, NY), then inserted into cells, separately. Briefly, One day prior to transfecting vector into cells, about $3 \times 10^{5}$ cells of overnight culture growing near confluence in 6-well plates were rinsed with PBS and re-suspended in serum-free DMEM. A solution of $1 \mu \mathrm{g}$ of the vector was incubated with $1 \mu \mathrm{L}$ volume of Lipofectamine transfection reagent (Clontech Laboratories, Inc., Palo Alto, CA) according to manufacturer instruction. Treated cells were incubated in complete medium overnight. Stable transfectants were selected with Geneticin (G418) by culturing in DMEM supplemented with $300 \mu \mathrm{g} / \mathrm{ml}$ of the antibiotic, for at least 10 days. Surviving cells were then harvested and seeded in new flasks with complete culture medium. Cells transfected with vector containing the full length SPTLC1 gene are designated as the "Iso" construct, the "CSPT" or "-75GFP" constructs have SPTLC1 recombinant vector modified at the C-terminal end with GFP. SPTLC1 expression was further validated by reverse transcription PCR analysis of RNA isolated from stable transfectants using Trizol reagent (Invitrogen, Carlsbad, CA).

\subsection{Primer Design and Polymerase Chain Reaction}

Total cellular RNA was prepared using the Trizol reagent (Invitrogen). Extracted RNA was used to generate cDNA using oligo (dT) primers or random primers and Superscript III reverse transcriptase (Invitrogen) accord- 
ing to the manufacturer's instructions. Primer pairs used for specifically amplifying the human SPTLC1 ORF (GenBank ACCESSION\#, Y08685) and AltORF (GenBank ACCESSION\#, HF583858) included: mSPTLC1 forward primer: 5'5'aggagtcactgaacactatg3',; reverse primer: 5'agctctctccagttcttcct3', pSPTLC1 forward primer: 5'aagaagccattatatactcatat3'; reverse primer: 5'ggcactgataagatcaata3'; both amplifying N- and C-terminal regions of the full length SPTLC1 sequence; SPTLC1AltORF forward primer: 5'ttaccaaatggtgtcagtatgg3', reverse primer: 5'aaaaatcagttcctgggcttt3' targeted the C-terminal region. The annealing temperature used for PCR amplification was $56^{\circ} \mathrm{C}$ for 35 cycles of PCR. Done in triplicates for each template, PCR reaction was optimized to ensure that a single band of the appropriate size is amplified and that no bands corresponding to primer-dimer pairs are present. In quantitative real time PCR (Q-RT-PCR), computer generated comparative threshold cycle $\left(\mathrm{C}_{\mathrm{t}}\right)$ values were used to derive relative quantity of each target gene expression, when compared with the housekeeping gene glyceraldehyde-3-phosphate dehydrogenase (GAPDH).

\subsection{DNA Sequencing}

The PCR products of genomic and cDNA templates were subjected to DNA sequence analysis (GENEWIZ, Inc., Cambridge, MA) and the nucleotide sequence data generated used for gene annotation using publicly available analysis software. Templates used for DNA sequencing were generated from SPTLC1 specific PCR amplification of reverse transcribed cDNA samples.

\subsection{Protein Isolation, Immunoprecipitation and PAGE}

Cells were lysed with immunoprecipitation RIPA buffer (Pierce Fisher Thermo Scientific, Rockford, IL) and total cell lysate, supplemented with protease inhibitor cocktail were stored frozen until used. Immunoprecipitation and electrophoretic analysis with $10 \%-12 \%$ polyacrylamide gel followed the manufacturer's protocol as previously described [14].

\subsection{Bioinformatics Analysis}

Publicly available computer programs and databases were used including: Pubmed (http://www.ncbi.nlm.nih.gov/pubmed/) a free resource for biomedical information; Cancer Genome Anatomy Project's Mitelman Database of Chromosome Aberrations and Gene Fusions in Cancer (http://www.cgap.nci.nih.gov/Chromosomes/Mitelman). The I-TASSER computer program (http://zhang.bioinformatics.ku.edu/I-TASSER) provided protein structure prediction. The UCSF Chimera computer program (http://www.cgl.ucsf.edu/chimera/download.html) was for sequence analysis. Protein expression was with Human Protein Atlas (http://www.proteinatlas.org/) [51].

\section{Results and Discussion}

\subsection{Localization of SPTLC1 in Inflammation-Associated Cancer Cell Lines}

As indicated in Table 1, using different analytical platforms, all cell lines tested have similar SPTLC1 expression profile.

As shown in Figure 2, the pattern of SPTLC1 immunostaining in fixed cells also correlates with the expression of SPTLC1 as a GFP chimera protein in the cytoplasm of recombinant cells. The GFP gene encodes a naturally fluorescent light-emitting chromophore and is a popular living marker for transiently and stably transfected clones in many studies.

\subsection{Molecular Characterization of SPTLC1 in Cancer Cell Lines}

The region of overlap between the ORF and AltORF of the SPTLC1 gene is illustrated in Figure 3. For a 2780 base pair long sequence, the AltORF aligns towards the C-terminal end of the ORF.

Transcriptional expression of the SPTLC1 AltORF was assessed in the current study, using PCR primer sets illustrated in Figure 4, designed to target a 100 base pair of the 120 base pair sequence.

The agarose gel images of Figure 5 show that the mSPTLC1 primer set that targets the ORF sequence successfully generated PCR amplicons from both genomic and cDNA templates from all the cell lines, except the MDA-PCa cell line template which did not generate detectable agarose gel signal. The pSPTLC1 primer set 


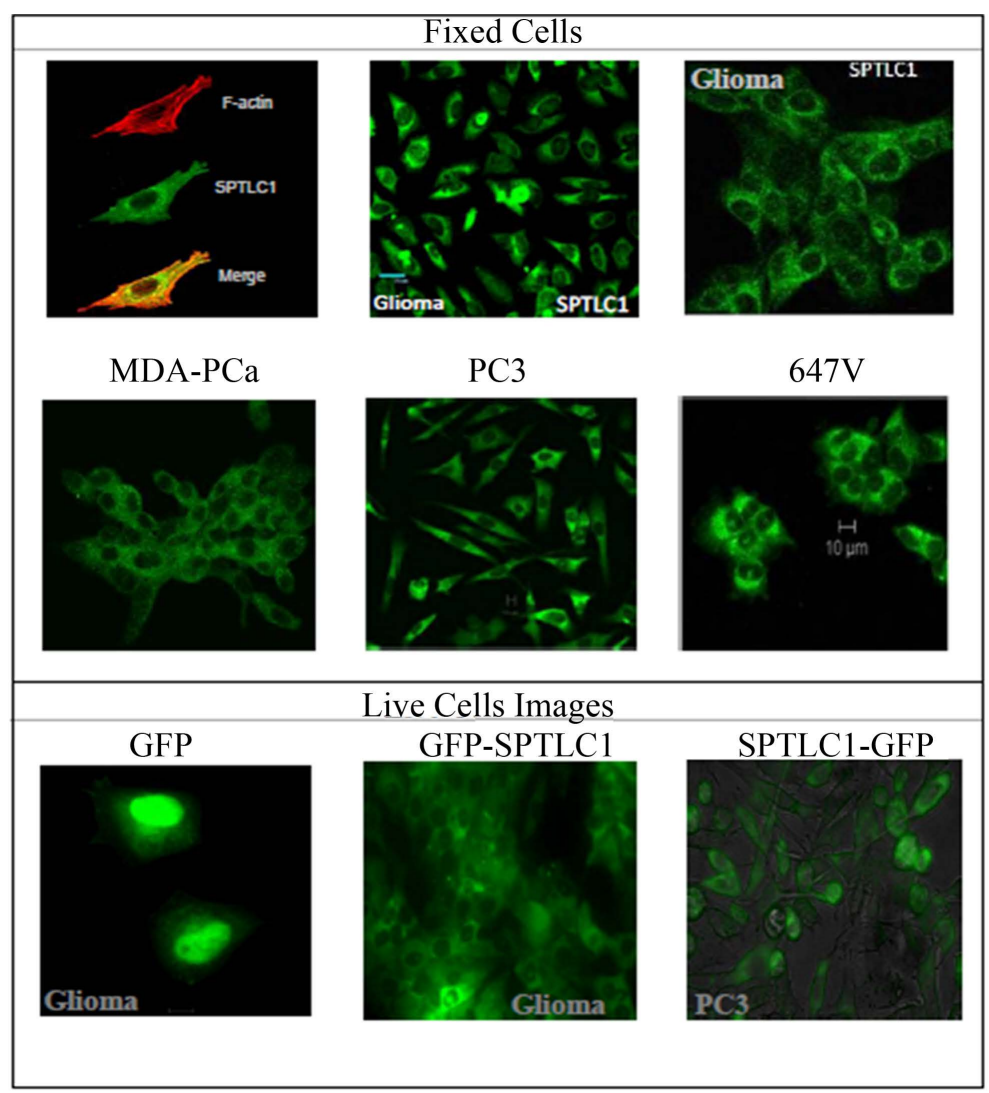

Figure 2. Localization of SPTLC1 in inflammation associated human cancer cell lines and their recombinant constructs. The localization of SPTLC1 is represented as green fluorescence, cytoskeleton is in red and nuclei in blue for fixed cells. Live imaging of cells expressing GFP or SPTLC1-GFP chimera protein is captured as green fluorescence signal. Profuse GFP expression at bottom left panel is in cell nucleus and cytoplasm, while recombinant SPTLC1-GFP is seen only in cell cytoplasm (bottom panel, middle and right). Images were captured at either $20 \times$ or $40 \times$.

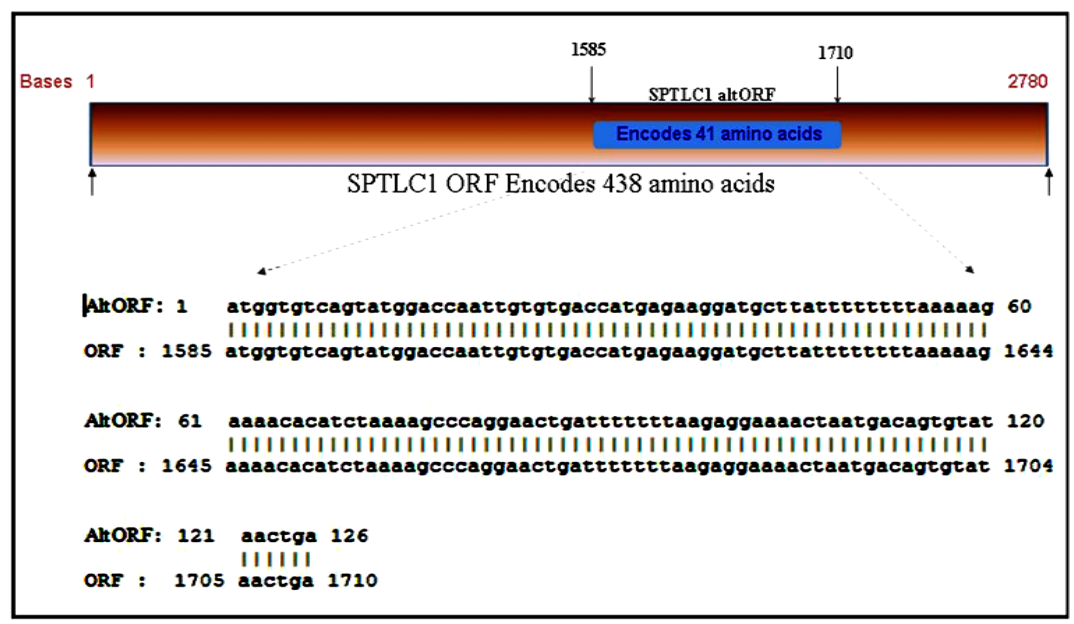

Figure 3. Sequence alignment of SPTLC1 reading frames. The SPTLC1 ORF encodes the long chain base SPTLC1 protein in the +3 reading frame while the SPTLC1 AltORF is in the +1 reading frame. The region of alignment for the AltORF sequence is at nucleotides (nt) 1585 to 1710 of the SPTLC1 ORF. 


\section{GATCTTTGATAGGATTGTTACCAAATGGTGTCAGTATGGACCAATTGTGTGACCATGAGA $\gg \gg \gg \gg \gg \gg \gg \gg \gg \gg \gg \gg \gg \gg$ \\ 61 AGGAIGCTTATTTTITTTAAAAAGAAAACACATCTAAAAGCCCAGGAACTGATTITTTTTA 《<<<<<<<<<<<<<<<<<<< 121 AGAGGAAACTAATGACAGTGTATAACTGATGTTTAAATTGTGCATTTAGTACTATTTAA}

Figure 4. Primer binding sites for the SPTLC1 AltORF. Key: “>>>>>” indicates the target region encompassed by the SPTLC1 AltORF PCR primer set used in the current study. The contiguous DNA sequence (contig) is indicated by a dashline box. This is the first reported use of a PCR primer set targeting the AltORF of SPTLC1 and functional characterization of the alternate reading frame in cancer cells of the inflammation-associated type.

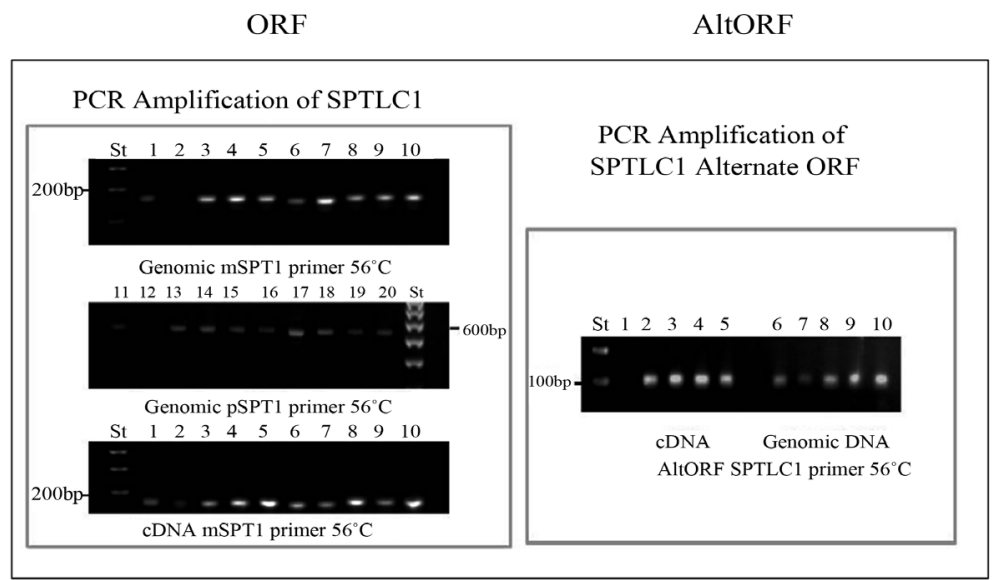

Figure 5. The SPTLC1 sequence is differentially amplified in cancer cells. Sample loading, for ORF: St is 100 bp standard; 1 and 11 are SKN-SH; 2 and 12 are MDA-PCa; 3 and 13 are Glioma; 4 and 14 are Glio-Iso; 5 and 15 are Glio CSPT; 6 and 16 are PC3; 7 and 17 are PC3-75GFP; 8 and 18 are 647V; 9 and 19 are 647VIso; 10 and 20 are 647V-CSPT. For the AltORF: St is 100bp standard; 1 and 6 are SKN-SH; 2 and 7 are MDA-PCa; 3 and 8 are Glioma; 4 and 9 are PC3; 5 and 10 are $647 \mathrm{~V}$. Genomic template is DNA isolated from cells and cDNA was generated by reverse transcription of random primed total RNA followed by PCR Amplification with SPTLC1 specific primer sets. Images are of ethidium bromide stained samples run in $2 \%$ agarose gel.

Table 1. Human cell lines screened for SPTLC1 expression and AltORF Sequence.

\begin{tabular}{cccc}
\hline Cell line & Source & SPTLC1 & Analysis method \\
\hline SKN-SH & Neuroblastoma & \pm & FCM; RT-PCR; DSA \\
MDA-PCa & Prostatic & \pm & FCM; ${ }^{*}$ RT-PCR; DSA \\
Glioma LN18 & Glioblastoma & \pm & FCM; RT-PCR; IP; DSA \\
PC3 & Prostatic & \pm & FCM; RT-PCR; ** DSA \\
647V & Urothelial & + & FCM; RT-PCR; DSA
\end{tabular}

Key: FCM, fluorescence confocal microscopy; RT-PCR, reverse transcription-polymerase chain re-action; IP, immunoprecipitation-PAGE; DSA, DNA sequence analysis of AltORF sequence. In staining protocol, each of the cell line was incubated on culture slide overnight to allow them ac-climatize. RNA was extracted from cells harvested from culture plates and then analyzed by RT-PCR. Lysate of total cellular protein were prepared for analysis by PAGE and Western blotting with anti-SPTLC1 antibody. "+" is used to indicate positive expression of SPTLC1 under all analytical procedures used. "+" indicates there was differential expression of SPTLC1 among the templates assayed. "“"” genomic DNA template of the MDA-PCa cell line did not generate detectable amplicon with PCR primer set targeting the ORF although the cDNA was detectably amplified with the same prime set. ${ }^{* * *}$ No sequence information was generated with cDNA sample of PC3 cells. 
which also targets the ORF sequence also generated detectable amplicons from cDNA templates of all the cell lines except the MDA-PCa cell line. In the same Figure 5 agarose gel image genomic template from all the cell lines generated PCR amplification of the SPTLC1 AltORF target, but was not detected in the SKN-SH cell line with the same primer set.

Transcriptional expression of the SPTLC1 AltORF in the cancer cell lines of this study was assessed by quantitative reverse transcription PCR (Q-RT-PCR) and the bar graph of Figure 6 reveals that each of the "Iso" recombinant cell line expresses higher relative SPTLC1 transcript levels, when compared to their parental counterpart. There is significantly lower relative transcriptional expression of the AltORF message in PC3 cells compared to the other parental cell lines or their SPTLC1 recombinants. The molecular basis for the differences in PCR and Q-RT-PCR profile could be due to cell specific genetic lesions that may result in modification of primer binding site, copy number variation, loss of zygosity or microsatellite instability at the C-terminal region of the SPTLC1 sequence. The relatively low amplification of PC3 SPTLC1 AltORF seen in Figure 6 was also accompanied by lack of AltORF nucleotide sequence information generated for the PC3 cDNA template as indicated in Figure 7. The GenBank nucleotide sequence of SPTLC1 AltORF is one with several short tandem repeat motifs. Such greater than two nucleotide repeats are characteristic of microsatellites and are known to exist as a prominent feature of a subset of human cancers [52]. The presence of nucleotide repeats in the SPTLC1 AltORF region suggests the region may be susceptible to MSI that could contribute to differences in genetic profile among the cell lines.

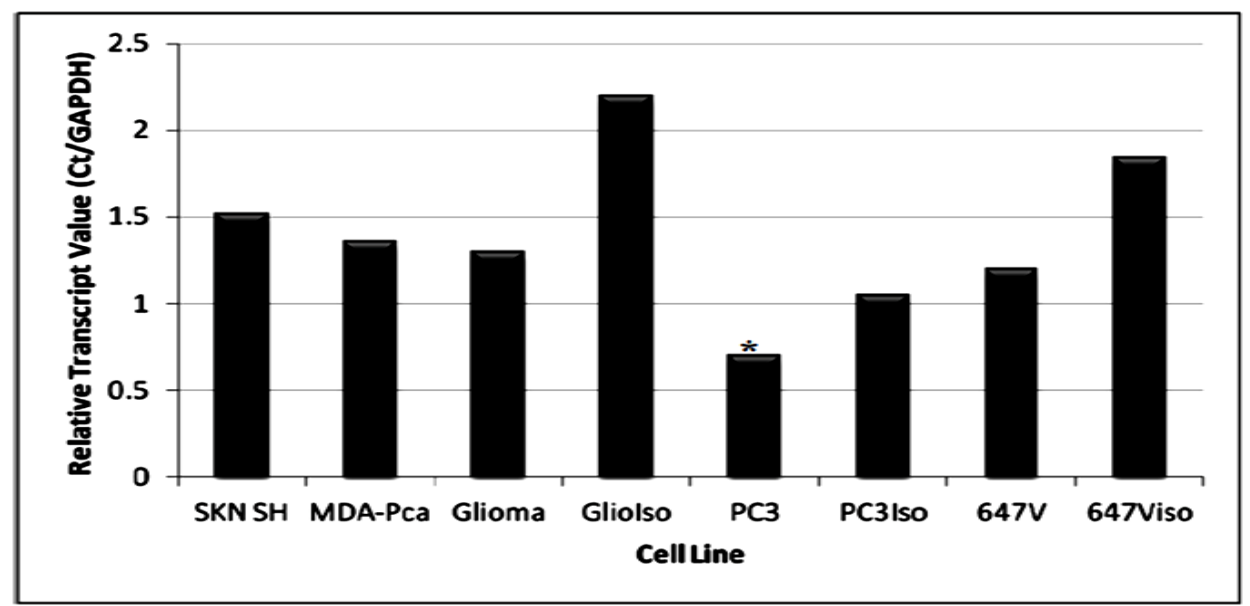

Figure 6. Q-RT-PCR assessment of SPTLC1 AltORF transcript expression. “*” indicates relative SPTLC1 transcript level significantly lower than that in all other cell lines. Equivalent amount of reverse transcribed cDNA generated from equal amount of RNA was used for quantitative PCR with the SPTLC1 AltORF-specific primer set. The bar graph was generated from relative SPTLC1 transcript levels (Ct) from the Q-RT-PCR assay, with the house-keeping glyceraldehyde-3-phosphate dehydrogenase (GAPDH) gene as control.

\begin{tabular}{|c|c|}
\hline Contig Sequence & 5'GCTTATTTTTTTTAAAAGAAAACACATCTAAAAGCCCAGGAACTGATT3' \\
\hline SKN cDNA altorfF & GCTTATTTTTTTTAAAAGAAAACACATCTAAAAGCCCAGGAACTGATT \\
\hline MDA cDNA altorfF & GCTTATTTTTTTTAAAAGAAAACACATCTAAAAGCCCAGGAACTGATT \\
\hline Glioma cDNA altorfF & GCTTATTTTTTTTAAAAGAAAACACATCTAAAAGCCCAGGAACTGATT \\
\hline $\begin{array}{l}647 \mathrm{~V} \text { cDNA altorfF } \\
\text { PC } 3 \text { cDNA altorfF }\end{array}$ & 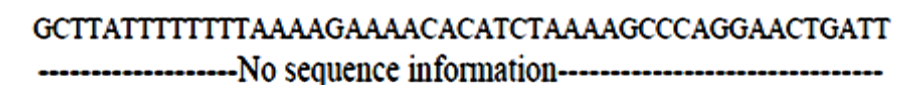 \\
\hline
\end{tabular}

Figure 7. DNA sequence analysis of the SPTLC1 AltORF. Sequences were generated from cDNA samples of reverse transcribed RNA samples from each of the cell line, using the forward primer for SPTLC1 AltORF, illustrated here. The contig sequence indicated in the figure was computer generated by sequence alignment. Nucleotide repeats including the A's and ATT in the sequence often constitute microsatellite regions known to be highly susceptible to genetic lesions, a common future of cancer cells [52]. 


\subsection{PAGE Analysis of Immunoprecipitated SPTLC1 Protein}

The Human Protein Atlas [51] lists a wide tissue and cell line distribution for the SPTLC1 protein based on studies with proliferating cells and malignant tissues. Figure 8 illustrates the image of a stained PAGE gel comparing protein bands of total cell lysate and SPTLC1 antibody mediated pull-down (immunoprecipitation) from the lysate of Glioma LN18 and SKN-SH cells. The antibody used to immunoprecipitate (IP) SPTLC1 from total cell lysate has been successfully used in immunoprecipitation and Western blot analysis [14] which can be applied for quantitative assessment of protein expression. However, the goal of the present study was only to detect SPTLC1 protein expression in the cell lines and the PAGE gel was stained directly for this qualitative assessment. The antibody used in the current study targets a major epitope at the N-terminal region of SPTLC1 identified by PAGE as a $53 \mathrm{kD}$ fragment, but there is evidence the antibody also recognizes a minor epitope at the C-terminal end of the long chain peptide fragment as evident in a $28 \mathrm{kD}$ fragment in PAGE assays. The relative mobility of IgG heavy chain and light-chain serum proteins in PAGE are detectable at about $50 \mathrm{kD}$ and 20 $\mathrm{kD}$ band regions, respectively. The amount of antibody serum loaded into lane 2 of Figure 8 is equivalent to the amount of antibody that was used in pulling down SPTLC1 protein loaded unto lanes 4, 6 and 8 . There is enhanced band intensity at the relative mobility region of $53 \mathrm{kD}$ where the SPTLC1 protein migrates, which is about a 5-fold increase when lane 2 is compared to the IP lanes 4, 6 and 8 bands in Figure 8. This observation is consistent with enhanced band intensity at the same region that has been reported with Western blot analysis of SPTLC1 [14]. Since the SPTLC1 antibody also recognizes a $25 \mathrm{kD}$ fragment (truncated protein), it is possible that this is responsible for the very closely aligned double band seen at the $20 \mathrm{kD}$ region of the IP lanes 4,6 and 8 of Figure 8.

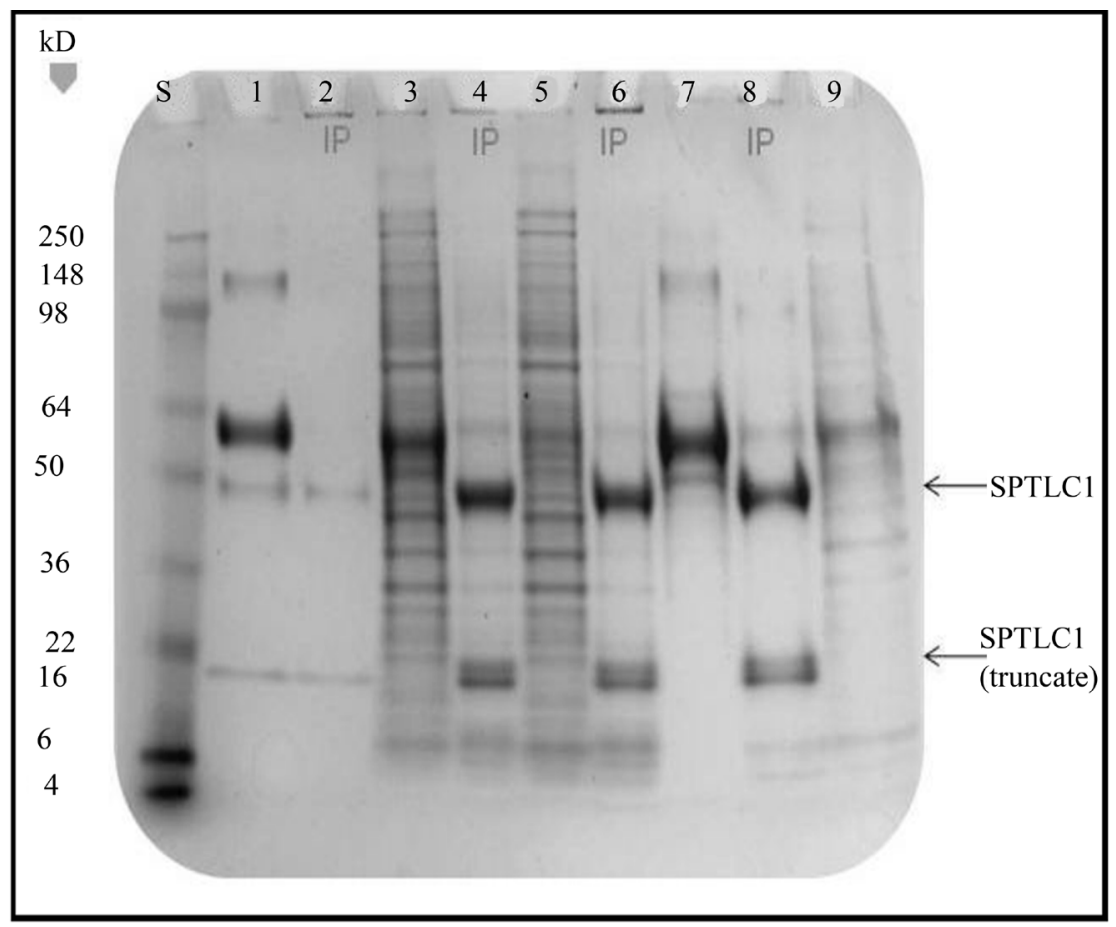

Figure 8. Immunoprecipitation-PAGE analysis of SPTLC1 expression. Lanes labeled "IP" were loaded with immunoprecipitate pulled down from cell lysate with the antibody against SPTLC1. Lane S, Protein Standard, Lane 1, Heavy and light IgG chain fragments in total antibody serum; Lane 2, IgG heavy and light chains eluted with Magnetic Beads; Lane 3, Total cell lysate of Glioma LN18 cells; Lane 4, SPTLC1 IP in wild type Glioma LN18 total cell lysate; Lane 5, total cell lysate of recombinant CSPT1-Glioma cells; Lane 6, SPTLC1 IP in recombinant CSPT1-Glioma cell lysate; Lane 7, total cell lysate from anchorage independent recombinant CSPT1-Glioma colonies; Lane 8, SPTLC1 IP in anchorage independent recombinant CSPT1-Glioma colonies; Lane 9, Total cell lysate of SKN-SH cells. 


\subsection{Bioinformatics Analysis of the SPTLC1 Gene and Encoded Protein}

The molecular function of the newly discovered SPTLC1 AltORF has not been investigated, but bioinformatics analysis suggests that the sequence encodes a truncated 43 amino acids peptide fragment. Illustrated in Figure 9 is a ribbon diagram for the putative fragment generated by the SPTLC1 AltORF sequence using the I-Tasser program. Functional domain search reveals that the fragment has KKKTH, a nuclear localization sequence (NLS); KKKT, which is a cAMP- and cGMP-dependent protein kinase phosphorylation site, and TMR, a protein kinase phosphorylation site. These domains can, potentially, add functional heterogeneity to the SPTLC1 gene product. It has a threonine $(\mathrm{T})$ residue located close to a C-terminal basic lysine (L) residue known to be targeted for phosphorylation by protein kinase C. The encoded alternate or truncated SPTLC1 fragment has the molecular characteristic, is longer than the standard 24 amino acids peptide minimum size threshold, but small enough for nuclear and focal adhesion localization.

\subsection{SPTLC1 and Disease-Associated Chromosome 9 Functional Linkage Group}

The expression of human SPTLC1 occurs within a very complex biological system involving metabolism, transport, intracellular signaling and cellular processes of stress response, survival and death [53]-[55], with genes close together on the same chromosome often encoding proteins having functional overlap [56]-[58]. Although SPTLC1 has not been directly identified as a cancer disease gene, several of the disease genes that map to chromosome 9 with SPTLC1, also exhibit considerable overlapping molecular functions. The genes highlighted in this report encode proteins that are either SPTLC1 binding partners such as ABCA1, ABCA2, SHC3, Edg3R, BIP/GRP78, ABL1, or are proteins that can engage in signaling crosstalk with it, such as DD3, PTCH1 or TGFBR1 (Table 2).

Another cluster of genes in the human chromosome 9q, proximate of SPTLC1 are highlighted in Table 3. As referenced above, there are reports indicating that SPTLC1 may interact directly or indirectly with the encoded proteins listed here. However, the extent to which an SPTLC1 encoded protein variant influences interaction with the proteins listed or the possible consequence on their signaling function in stress response is not fully known.

\subsection{A Schematic of Emerging Human SPTLC1 Interactome}

The protein interactome schematic of Figure 10 was derived using reports from immunofluorescence staining,

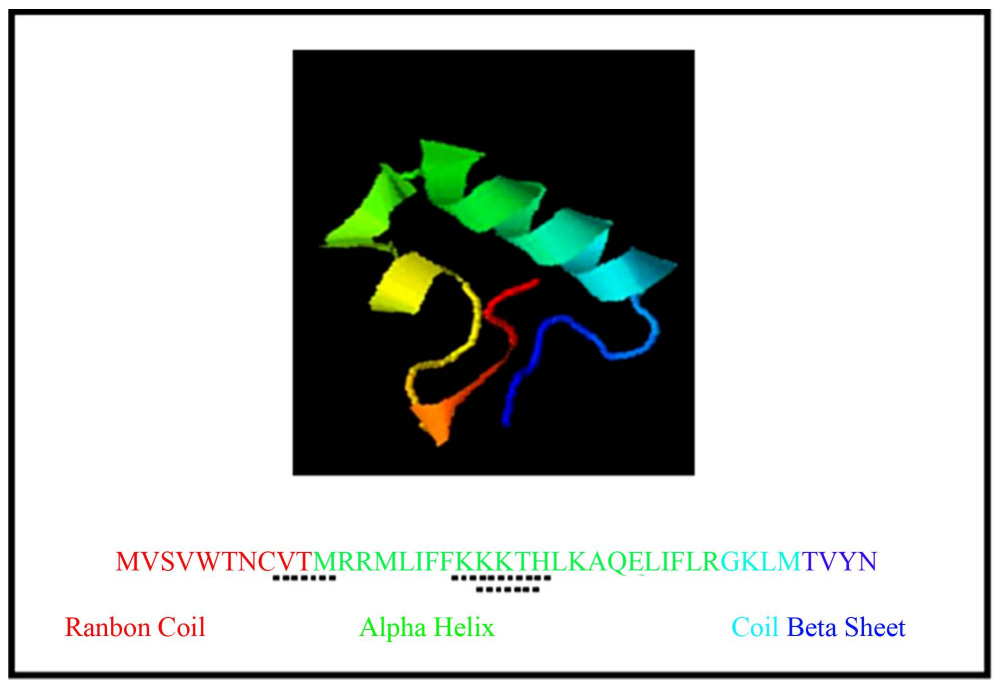

Figure 9. Ribbon diagram predicted for human SPTLC1 AltORF translation product. The protein structure was predicted with the I-TASSER program, from the amino acid sequence of the peptide encoded by the SPTLC1 AltORF. Random coil is in red, alpha helix in green and beta sheet in blue. Colorcoded amino acid sequence is aligned with the predicted secondary structure. Predicted functional domains are underlined in broken lines. 


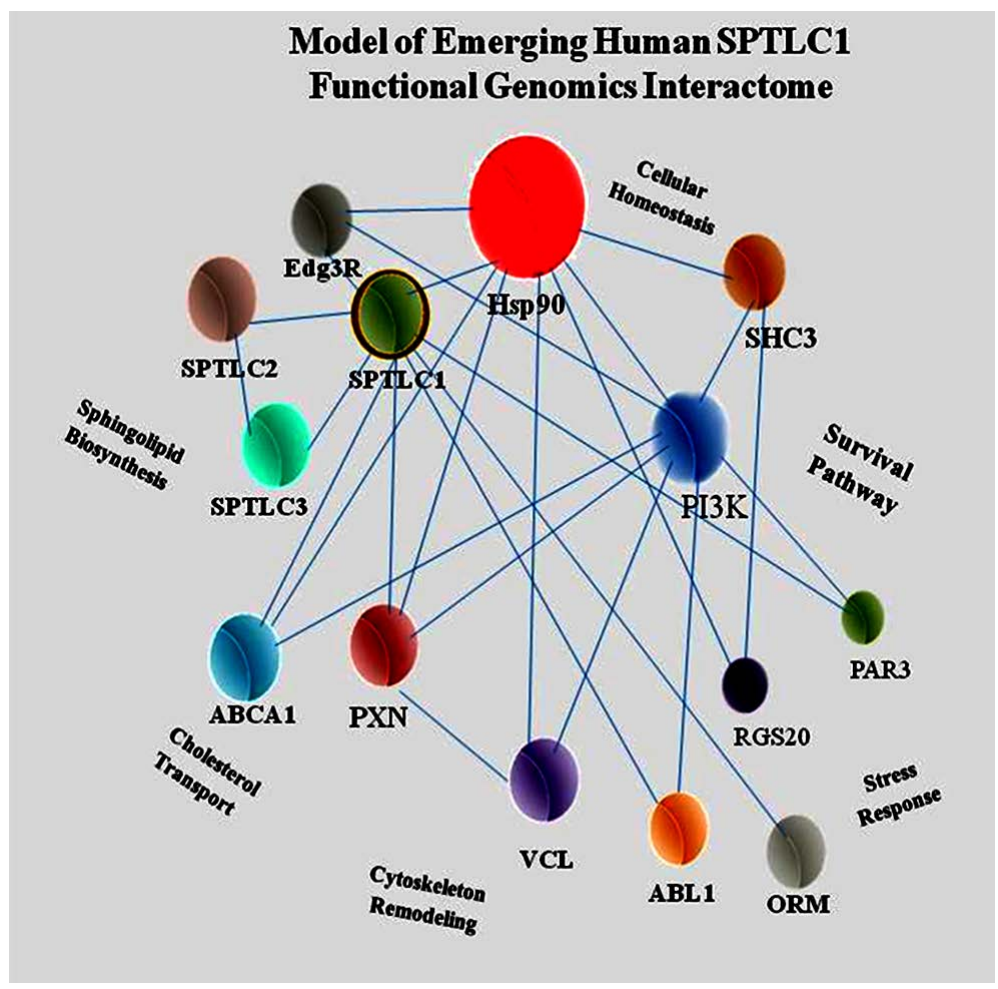

Figure 10. Schematic of emerging human SPTLC1 interactome. ABCA1, ATP-binding cassette transporter 1; ABL1, c-abl oncogene 1; Edg3, endothelial differentiation G-protein coupled receptor 3; Hsp90, 90 kiloDalton heat shock protein; ORM, orosomucoid 1; PAR3, pulmonary adenoma resistance 3; PXN, paxillin; PI3K, phosphatidylinositol-4,5-bisphosphate 3-kinase; SHC3, Src homology containing 3 domain; RGS20, regulator of G-protein signaling protein 20; SPTLC variants 1, 2 and 3; VCL, vinculin.

Table 2. SPTLC1 has functional linkage genes at human chromosome 9q22 region.

\begin{tabular}{|c|c|c|}
\hline Gene & Cytogenetic band locus & Known and putative functional genomics \\
\hline $\begin{array}{c}\text { SPTLC1 } \\
\text { Serine palmitoyltransferase } 1\end{array}$ & 9q22.2/22.31 & $\begin{array}{l}\text { Patients with severe HSN1 have disease-associated SPTLC1 mutations [4] [7] } \\
\text { [15]. Some mutations are implicated in enzyme catalytic promiscuity that leads } \\
\text { to accumulation of neurotoxic sphinganines in plasma samples and } \\
\text { recombinant HEK293T cells [8] [9]. }\end{array}$ \\
\hline $\begin{array}{l}\text { TGFBR1 } \\
\text { Transforming growth factor, beta } \\
\text { receptor } 1\end{array}$ & $9 q 22$ & $\begin{array}{l}\text { Encoded protein forms heteromeric complex with type II TGF-beta receptors } \\
\text { when bound to TGF-beta. Transduces TGF-beta signal from cell surface to the } \\
\text { cytoplasm. Mutation in TGFBR1 known to alter TGF- } \beta \text { signaling, promote } \\
\text { tumorigenesis and increase risk for Breast cancer [47] [59]. }\end{array}$ \\
\hline $\begin{array}{l}\text { SHC3 } \\
\text { Src homology containing } 3 \\
\text { domain }\end{array}$ & $9 q 22.1$ & $\begin{array}{l}\text { Encodes a docking protein important in signaling pathways regulating cellular } \\
\text { proliferation, survival and differentiation. The interaction of SHC3 and Edg3R } \\
\text { is important in cancer progression [60]. The SHC3 domain of SPTLC1 may } \\
\text { allow crosstalk with EDG3. }\end{array}$ \\
\hline $\begin{array}{c}\text { Edg3R (S1P3) } \\
\text { Endothelial differentiation } \\
\text { G-protein coupled receptor } 3\end{array}$ & 9q22.1 - 22.2 & $\begin{array}{c}\text { Family of Edg receptors signal cellular proliferation, morphology and are } \\
\text { involved in inflammation [61]-[63]. Edg3 signals through G-protein to } \\
\text { downstream events of Rho, Ras, PKC and PI3K [64]. The EDG3 and SHC3 } \\
\text { genes at 9q22.1 encode proteins whose interaction is implicated in cancer } \\
\text { progression [44] [60]. }\end{array}$ \\
\hline $\begin{array}{c}\text { Patch } 1 \text { (PTCH1) } \\
\text { Negative regulator patched } 1\end{array}$ & $9 q 22.3$ & $\begin{array}{c}\text { One of cytoplasmic receptors for a number of hedgehog proteins implicated in } \\
\text { tumorigenesis [41]. A tumor suppressor mutation in PTCH1 is implicated in } \\
\text { increased constitutive activity of growth promoting Hedgehog signaling in } \\
\text { urothelial carcinoma [65]. }\end{array}$ \\
\hline
\end{tabular}


Table 3. SPTLC1 has functional linkage genes proximate of human chromosome 9q22 region.

\begin{tabular}{|c|c|c|}
\hline Gene & Cytogenetic band locus & Known and putative functional genomics \\
\hline $\begin{array}{c}\text { DD3 or PCA3 } \\
\text { Prostate cancer antigen } 3\end{array}$ & 9q21.2 & $\begin{array}{l}\text { Non coding and highly over-expressed in Prostate Cancer specimens [45] [46]. No } \\
\text { known relationship with SPTLC1 although in close genomic proximity. }\end{array}$ \\
\hline $\begin{array}{l}\text { BIP/GRP78 } \\
78 \mathrm{kDa} \text { glucose-regulated } \\
\text { protein. }\end{array}$ & $9 q 33.3$ & $\begin{array}{l}\text { An ER lumen integrated stress response-related protein, implicated in the unfolded } \\
\text { protein response and cancer progression pathways [66]. It binds SPTLC1 in Hek3 } \\
\text { human kidney cancer cell line [3]. }\end{array}$ \\
\hline $\begin{array}{c}\text { ABL1 } \\
\text { c-abl oncogene } 1\end{array}$ & $9 q 34.1$ & $\begin{array}{l}\text { A non-receptor tyrosine-protein kinase linked to key processes regulating cell } \\
\text { differentiation, division, adhesion, motility, stress response and death. Reciprocal } \\
\text { translocation of ABL1 oncogene to 22q11 creates the BCR/ABL1 fusion gene, a } \\
\text { cytogenetic hallmark of chronic myeloid leukemia [48] [67]. ABL phosphorylates } \\
\text { SPTLC1 at Tyr(164). Mutating Tyr(164) to Phe in SPTLC1, increasing SPT enzyme } \\
\text { activity and apoptotic sensitization of cultured K562 cells [68] [69]. }\end{array}$ \\
\hline
\end{tabular}

co-localization, antibody pull-down, bioinformatics analysis and functional genomics studies. The lines join interacting protein partners in designated functional modules (e.g. cellular homeostasis). The scheme also shows that a single stress stimulus can impact multiple signaling pathways. The interactome highlights the potential for SPTLC1 contributing to multiple biologic functions through heterocomplex formation and/or crosstalk with structural, transport or signaling proteins regulating diverse cellular processes. For example, cell morphology can be modified through interaction with structural and scaffolding proteins, cell behavior through kinases and nuclear proteins in regulating transcriptional expression. Interaction of SPTLC1 protein with those encoded by genes linked to SPTLC1, such as the orosomucoid 1 (ORM1) gene which encodes a putative signaling protein over-expressed in acute inflammation [70], or ABCA1 [24] in cholesterol transport also has functional implications. In Saccharomyces interaction of ORM with SPTLC1 is reported to regulate the homeostasis of bioactive sphingolipids [71]. However, all the SPTLC1 interactome for its chromosome 9 linkage group has not been determined.

\section{Conclusion}

The temporal-spatial localization and molecular profile of the human SPTLC1 highlighted in this study is that of an emerging stress responsive protein capable of modulating cellular behavior through a protein interactome conducive to the progression of the malignant phenotype in inflammation associated cancers. Parental cancer cell lines and their SPTLC1 recombinant counterparts provided a useful cell model for assessing global expression profiles of the SPTLC1 gene. The similarity in the cytoplasmic sub-cellular localization of SPTLC1 as detected by immunostaining and expression as a GFP chimera protein is consistent with a wide tissue distribution for the protein. Differences in molecular profile among the cell lines based on PCR amplification and sequence data may be due to the effect of different genetic lesions in the gene sequence. In particular, microsatellite instability at the AltORF sequence is often seen in human cancers [51]. However, since all the cell lines examined in this study show positive immunostaining for SPTLC1 expression, post-translational modification cannot be ruled out as a factor that can modulate the molecular function of SPTLC1. Bioinformatics analysis of the human SPTLC1 AltORF identifies functional phosphorylation and localization domains that may be relevant to its functional genomics. Protein kinase $\mathrm{C}$ has been found from in vivo studies to exhibit a preference for the phosphorylation of serine or threonine residues found close to a C-terminal basic residue [53]. The abnormal phosphorylation of the SPTLC1AltORF fragment could lead to conformational perturbation of both SPTLC1 and any of its binding partners, with implications for altered regulation of cellular behavior. This study provides a first functional genomics evidence for the transcriptional expression of the SPTLC1 AltORF based on PCR amplification of both the genomic sequence and the reverse transcribed mRNA. Several putative microsatellites exist in the SPTLC1 AltORF sequence making it a region susceptible to instability, but it remains to be determined if this contributes to differences in SPTLC1 molecular profile. Together, the findings of the current study provide additional insight into the molecular profile of SPTLC1 that will contribute to better understanding the molecular mechanisms by which its spatial distribution and binding characteristics may be integrated into shared biological processes. 


\section{Authors' Contributions}

TY is the principal investigator on this project, he conceived, designed and coordinated the study, he cultured cells and generated the recombinant constructs for use in confocal imaging, molecular analysis. He was responsible for drafting the manuscript. TN contributed to the molecular genetic studies for the SPTLC1 ORF, worked on the sequence alignment and drafting of the manuscript. CJ is student and contributed to the molecular genetic studies for the SPTLC1 AltORF, participated in the sequence alignment and drafting of the manuscript. All authors read and approved the final manuscript.

\section{Acknowledgements and Funding}

Dr. Carmen Sidbury, Dean for Research and Director of Title III Program at Spelman College, provided funding support, in part, through the NSF/ASPIRE HBCU-UP Summer Program Award \#HRD-0714553, which allowed the purchase of reagents used in this project. Dr. Tiffany Oliver provided the critical support needed for getting samples sequenced for this study.

\section{References}

[1] Carton, J.M., Uhlinger, D.J., Batheja, A.D., Derian, C., Ho, G., Argenteri, D. and D’Andrea, M.R. (2003) Enhanced Serine Palmitoyltransferase Expression in Proliferating Fibroblasts, Transformed Cell Lines and Human Tumors. Journal of Histochemistry Cytochemistry, 51, 715-726. http://dx.doi.org/10.1177/002215540305100603

[2] Batheja, A.D., Uhlinger, D.J., Carton, J.M., Ho, G. and D’Andrea, M.R. (2003) Characterization of Serine Palmitoyltransferases in Normal Human Tissues. Journal of Histochemistry Cytochemistry, 51, 687-696. http://dx.doi.org/10.1177/002215540305100514

[3] Wei, J., Yerokun, T., Leipelt, M., Haynes, C., Radhakrishna, H., Merrill, A.H., et al. (2009) Serine Palmitoyltransferase Subunit 1 Is Present in the Endoplasmic Reticulum, Nucleus and Focal Adhesions, and Functions in Cell Morphology. Biochimica et Biophysica Acta (BBA)—Molecular and Cell Biology of Lipids, 1791, 746-756. http://dx.doi.org/10.1016/j.bbalip.2009.03.016

[4] Bejaoui, K., Wu, C., Scheffler, M.D., Haan, G., Ashby, P., Wu, L., de Jong, P. and Brown Jr., R.H. (2001) SPTLC1 Is Mutated in Hereditary Sensory Neuropathy, Type 1. Nature Genetics, 27, 261-262. http://dx.doi.org/10.1038/85817

[5] Dawkins, J.L., Hulme, D.J., Brahmbhatt, S.B., Auer-Grumbach, M. and Nicholson, G.A. (2001) Mutations in SPTLC1, Encoding Serine Palmitoyltransferase, Long Chain Base Subunit-1, Cause Hereditary Sensory Neuropathy Type I. Nature Genetics, 27, 309-312. http://dx.doi.org/10.1038/85879

[6] Verhoeven, K., Coen, K., De Vriendt, E., Jacobs, A., Van Gerwen, V., Smouts, I., et al. (2004) SPTLC1 Mutation in Twin Sisters with Hereditary Sensory Neuropathy Type I. Neurology, 62, 1001-1002.

http://dx.doi.org/10.1212/01.WNL.0000115388.10828.5C

[7] Hornemann, T., Penno, A., Richard, S., Nicholson, G., van Dijk, F.S., Rotthier, A., Timmerman, V. and von Eckardstein, A. (2009) A Systematic Comparison of All Mutations in Hereditary Sensory Neuropathy Type I (HSAN I) Reveals That the G387A Mutation Is Not Disease Associated. Neurogenetics, 10, 135-143. http://dx.doi.org/10.1007/s10048-008-0168-7

[8] Penno, A., Reilly, M.M., Houlden, H., Laurá, M., Rentsch, K., Niederkofler, V., et al. (2010) Hereditary Sensory Neuropathy Type 1 Is Caused by the Accumulation of Two Neurotoxic Sphingolipids. The Journal of Biological Chemistry, 285, 11178-11187. http://dx.doi.org/10.1074/jbc.M109.092973

[9] Rotthier, A., Penno, A., Rautenstrauss, B., Auer-Grumbach, M., Stettner, G.M., Asselbergh, B., et al. (2011) Characterization of Two Mutations in the SPTLC1 Subunit of Serine Palmitoyltransferase Associated with Hereditary Sensory and Autonomic Neuropathy Type I. Human Mutation, 32, E2211-E2225. http://dx.doi.org/10.1126/science.1067122

[10] Taylor, J.P., Hardy, J. and Fishbeck, K.H. (2002) Toxic Proteins in Neurodegenerative Disease. Science, 296, 19911995.

[11] Auer-Grumbach, M. (2008) Hereditary Sensory Neuropathy Type I. Orphanet Journal of Rare Diseases, 3, 7-13. http://dx.doi.org/10.1186/1750-1172-3-7

[12] Hannun, Y.A., Luberto, C. and Argraves, K.M. (2001) Enzymes of Sphingolipid Metabolism: From Modular to Integrative Signaling. Biochemistry, 40, 4893-4903. http://dx.doi.org/10.1021/bi002836k

[13] Weiss, B. and Stoffell, W. (1997) Human and Murine Serine-Palmitoyl-CoA Transferase-Cloning, Expression and Characterization of the Key Enzyme in Sphingolipid Synthesis. European Journal of Biochemistry, 249, 239-247. http://dx.doi.org/10.1111/j.1432-1033.1997.00239.x 
[14] Yerokun, T. and Stewart, J. (2006) Novel Functional Association of Serine Palmitoyltransferase Subunit 1-A Peptide in Sphingolipid Metabolism with Cytochrome P4501A1 Transactivation and Proliferative Capacity of the Human Glioma LN18 Brain Tumor Cell Line. International Journal of Environmental Research and Public Health, 3, 252-261. http://dx.doi.org/10.3390/ijerph2006030030

[15] Humphray, S.J., Oliver, K., Hunt, A.R., Plumb, R.W., Loveland, J.E., Howe, K.L., et al. (2004) DNA Sequence and Analysis of Human Chromosome 9. Nature, 429, 369-374. http://dx.doi.org/10.1038/nature02465

[16] Crespo, I., Vital, A.L., Nieto, A.B., Rebelo, O., Tão, H., Lopes, M.C., et al. (2011) Detailed Characterization of Alterations of Chromosomes 7, 9, and 10 in Glioblastoma as Assessed by Single-Nucleotide Polymorphism Arrays. Journal of Molecular Diagnostics, 13, 634-647. http://dx.doi.org/10.1016/j.jmoldx.2011.06.003

[17] Leo, C. and Chen, J.D. (2000) The SRC Family of Nuclear Receptor Coactivators. Gene, 245, 1-11. http://dx.doi.org/10.1016/S0378-1119(00)00024-X

[18] Liu, J., Liao, Z., Camden, J., Griffin, K.D., Garrad, R.C., Santiago-Perez, L.I., González, F.A., Seye, C.I., Weisman, G.A. and Erb, L. (2004) Src Homology 3 Binding Sites in the P2Y2 Nucleotide Receptor Interact with Src and Regulate Activities of Src, Pyk2, and Growth Factor Receptors. Journal of Biological Chemistry, 279, 8212-8218. http://dx.doi.org/10.1074/jbc.M312230200

[19] Oyama, M., Itagaki, C., Hata, H., Suzuki, Y., Izumi, T., Natsume, T., Isobe, T. and Sugano, S. (2004) Analysis of Small Human Proteins Reveals the Translation of Upstream Open Reading Frames of mRNAs. Genome Research, 14, 2048-2052. http://dx.doi.org/10.1101/gr.2384604

[20] Oyama, M., Kozuka-Hata, H., Suzuki, Y., Semba, K., Yamamoto, T. and Sugano, S. (2007) Diversity of Translation Start Sites May Define Increased Complexity of the Human Short ORFeome. Molecular \& Cellular Proteomics, 6, 1000-1006. http://dx.doi.org/10.1074/mcp.M600297-MCP200

[21] Vanderperre, B., Lucier, J.F. and Roucou, X. (2012) HAltORF: A Database of Predicted Out-of-Frame Alternative Open Reading Frames in Human. Database (Oxford), 2012, bas025. http://dx.doi.org/10.1093/database/bas025

[22] Futerman, A.H. and Hannun, Y.A. (2004) The Complex Life of Simple Sphingolipids. EMBO Reports, 5, 777-782. http://dx.doi.org/10.1038/sj.embor.7400208

[23] Hornemann, T., Wei, Y. and von Eckardstein, A. (2007) Is the Mammalian Serine Palmitoyltransferase a High-Molecular-Mass Complex? Biochemical Journal, 405, 157-164.

[24] Tamehiro, N., Zhou, S., Okuhira, K., Benita, Y., Brown, C.E., Zhuang, D.Z., Latz, E., Hornemann, T., von Eckardstein, A., Xavier, R.J., Freeman, M.W. and Fitzgerald, M.L. (2008) SPTLC1 Binds ABCA1 to Negatively Regulate Trafficking and Cholesterol Efflux Activity of the Transporter. Biochemistry, 47, 6138-6147. http://dx.doi.org/10.1021/bi800182t

[25] Chang, H.Y., Sneddon, J.B., Alizadeh, A.A., Sood, R., West, R.B., Montgomery, K., Chi, J.T., van de Rijn, M., Botstein, D. and Brown, P.O. (2004) Gene Expression Signature of Fibroblast Serum Response Predicts Human Cancer Progression: Similarities between Tumors and Wounds. PLoS Biology, 2, Article ID: e7. http://dx.doi.org/10.1371/journal.pbio.0020007

[26] Rangarajan, E.S. and Izard, T. (2012) The Cytoskeletal Protein $\alpha$-Catenin Unfurls upon Binding to Vinculin. Journal of Biological Chemistry, 287, 18492-18499. http://dx.doi.org/10.1074/jbc.M112.351023

[27] Ewing, R.M., Chu, P., Elisma, F., Li, H., Taylor, P., Climie, S., et al. (2007) Large-Scale Mapping of Human ProteinProtein Interactions by Mass Spectrometry. Molecular Systems Biology, 3, 89. http://dx.doi.org/10.1038/msb4100134

[28] Abramow-Newerly, M., Roy, A.A., Nunn, C. and Chidiac, P. (2006) RGS Proteins Have a Signaling Complex: Interactions between RGS Proteins and GPCRs, Effectors, and Auxiliary Proteins. Cellular Signalling, 18, 579-591. http://dx.doi.org/10.1016/j.cellsig.2005.08.010

[29] Riker, A.I., Enkemann, S.A., Fodstad, O., Liu, S., Ren, S., Morris, C., et al. (2008) The Gene Expression Profiles of Primary and Metastatic Melanoma Yield a Transition Point of Tumor Progression and Metastasis. BMC Medical Genomics, 1, 13. http://dx.doi.org/10.1186/1755-8794-1-13

[30] Tamehiro, N., Mujawar, Z., Zhou, S., Zhuang, D.Z., Hornemann, T., von Eckardstein, A. and Fitzgerald, M.L. (2009) Cell Polarity Factor Par3 Binds SPTLC1 and Modulates Monocyte Serine Palmitoyltransferase Activity and Chemotaxis. Journal of Biological Chemistry, 284, 24881-24890. http://dx.doi.org/10.1074/jbc.M109.014365

[31] Hirose, T., Karasawa, M., Sugitani, Y., Fujisawa, M., Akimoto, K., Ohno, S. and Noda, T. (2006) PAR3 Is Essential for Cyst-Mediated Epicardial Development by Establishing Apical Cortical Domains. Development, 133, 1389-1398. http://dx.doi.org/10.1242/dev.02294

[32] Sfakianos, J., Togawa, A., Maday, S., Hull, M., Pypaert, M., Cantley, L., Toomre, D. and Mellman, I. (2007) Par3 Functions in the Biogenesis of the Primary Cilium in Polarized Epithelial Cells. Journal of Cell Biology, 179, 11331140. http://dx.doi.org/10.1083/jcb.200709111

[33] Marcil, M., Brooks-Wilson, A., Clee, S.M., Roomp, K., Zhang, L.H., Yu, L., et al. (1999) Mutations in the ABC1 
Gene in Familial HDL Deficiency with Defective Cholesterol Efflux. Lancet, 354, 1341-1346. http://dx.doi.org/10.1016/S0140-6736(99)07026-9

[34] Luciani, M.F., Denizot, F., Savary, S., Mattei, M.G. and Chimini, G. (1994) Cloning of Two Novel ABC Transporters Mapping on Human Chromosome 9. Genomics, 21, 150-159. http://dx.doi.org/10.1006/geno.1994.1237

[35] Maruno, M., Yoshimine, T., Muhammad, A.K., Tokiyoshi, K. and Hayakawa, T. (1996) Loss of Heterozygosity of Microsatellite Loci on Chromosome 9p in Astrocytic Tumors and Its Prognostic Implications. Journal of NeuroOncology, 30, 19-24. http://dx.doi.org/10.1007/BF00177439

[36] Bulashevska, S., Szakacs, O., Brors, B., Eils, R. and Kovacs, G. (2004) Pathways of Urothelial Cancer Progression Suggested by Bayesian Network Analysis of Allelotyping Data. International Journal of Cancer, 110, 850-856. http://dx.doi.org/10.1002/ijc.20180

[37] Gudmundsson, J., Sulem, P., Gudbjartsson, D.F., Jonasson, J.G., Sigurdsson, A., Bergthorsson, J.T., et al. (2009) Common Variants on 9q22.33 and 14q13.3 Predispose to Thyroid Cancer in European Populations. Nature Genetics, 41, 460-464. http://dx.doi.org/10.1038/ng.339

[38] Jones, A.M., Howarth, K.M., Martin, L., Gorman, M., Mihai, R., Moss, L., et al. (2012) Thyroid Cancer Susceptibility Polymorphisms: Confirmation of Loci on Chromosomes 9q22 and 14q13, Validation of a Recessive 8q24 Locus and Failure to Replicate a Locus on 5q24. Journal of Medical Genetics, 49, 158-163. http://dx.doi.org/10.1136/jmedgenet-2011-100586

[39] Warren, H., Dudbridge, F., Fletcher, O., Orr, N., Johnson, N., Hopper, J.L., et al. (2012) 9q31.2-rs865686 as a Susceptibility Locus for Estrogen Receptor-Positive Breast Cancer: Evidence from the Breast Cancer Association Consortium. Cancer Epidemiology, Biomarkers \& Prevention, 21, 1783-1791. http://dx.doi.org/10.1158/1055-9965.EPI-12-0526

[40] Sinha, S., Singh, R.K., Alam, N., Roy, A., Roychoudhury, S. and Panda, C.K. (2008) Alterations in Candidate Genes PHF2, FANCC, PTCH1 and XPA at Chromosomal 9q22.3 Region: Pathological Significance in Early- and Late-Onset Breast Carcinoma. Molecular Cancer, 7, 84. http://dx.doi.org/10.1186/1476-4598-7-84

[41] Byrom, J., Mudaliar, V., Redman, C.W., Jones, P., Strange, R.C. and Hoban, P.R. (2004) Loss of Heterozygosity at Chromosome 9q22-31 Is a Frequent and Early Event in Ovarian Tumors. International Journal of Oncology, 24, 1271-1277.

[42] Kemp, Z.E., Carvajal-Carmona, L.G., Barclay, E., Gorman, M., Martin, L., Wood, W., et al. (Colorectal Tumour Gene Identification Study Consortium) (2006) Evidence of Linkage to Chromosome 9q22.33 in Colorectal Cancer Kindreds from the United Kingdom. Cancer Research, 66, 5003-5006. http://dx.doi.org/10.1158/0008-5472.CAN-05-4074

[43] Majewski, T., Lee, S., Jeong, J., Yoon, D.S., Kram, A., Kim, M.S., et al. (2008) Understanding the Development of Human Bladder Cancer by Using a Whole-Organ Genomic Mapping Strategy. Laboratory Investigation, 88, 694-721. http://dx.doi.org/10.1038/labinvest.2008.27

[44] Takuwa, Y., Takuwa, N. and Sugimoto, N. (2002) The Edg Family G Protein-Coupled Receptors for Lysophospholipids: Their Signaling Properties and Biological Activities. Journal of Biochemistry, 131, 767-771. http://dx.doi.org/10.1093/oxfordjournals.jbchem.a003163

[45] Bussemakers, M.J., van Bokhoven, A., Verhaegh, G.W., Smit, F.P., Karthaus, H.F., Schalken, J.A., Debruyne, F.M., Ru, N. and Isaacs, W.B. (1999) DD3: A New Prostate-Specific Gene, Highly Overexpressed in Prostate Cancer. Cancer Research, 59, 5975-5979.

[46] Väänänen, R.M., Lilja, H., Cronin, A., Kauko, L., Rissanen, M., Kauko, O., Kekki, H., Vidbäck, S., Nurmi, M., Alanen, K. and Pettersson, K. (2013) Association of Transcript Levels of 10 Established or Candidate-Biomarker Gene Targets with Cancerous versus Non-Cancerous Prostate Tissue from Radical Prostatectomy Specimens. Clinical Biochemistry, 46, 670-674. http://dx.doi.org/10.1016/j.clinbiochem.2013.01.019

[47] Wang, Y.Q., Qi, X.W., Wang, F., Jiang, J. and Guo, Q.N. (2012) Association between TGFBR1 Polymorphisms and Cancer Risk: A Meta-Analysis of 35 Case-Control Studies. PLoS ONE, 7, Article ID: e42899. http://dx.doi.org/10.1371/journal.pone.0042899

[48] Sirvent, A., Benistant, C. and Roche, S. (2008) Cytoplasmic Signalling by the c-Abl Tyrosine Kinase in Normal and Cancer Cells. Biology of the Cell, 100, 617-631. http://dx.doi.org/10.1042/BC20080020

[49] Fletcher, O., Johnson, N., Orr, N., Hosking, F.J., Gibson, L.J., Walker, K., et al. (2011) Novel Breast Cancer Susceptibility Locus at 9q31.2: Results of a Genome-Wide Association Study. Journal of the National Cancer Institute, 103, 425-435. http://dx.doi.org/10.1093/jnci/djq563

[50] Antoniou, A.C., Kuchenbaecker, K.B., Soucy, P., Beesley, J., Chen, X., McGuffog, L., et al. (2012) Common Variants at 12p11, 12q24, 9p21, 9q31.2 and in ZNF365 Are Associated with Breast Cancer Risk for BRCA1 and/or BRCA2 Mutation Carriers. Breast Cancer Research, 14, R33. http://dx.doi.org/10.1186/bcr3121

[51] Uhlen, M., Oksvold, P., Fagerberg, L., Lundberg, E., Jonasson, K., Forsberg, M., Zwahlen, M., Kampf, C., Wester, K., Hober, S., Wernerus, H., Björling, L. and Ponten, F. (2012) Towards a Knowledge-Based Human Protein Atlas. Nature 
Biotechnology, 28, 1248-1250. http://dx.doi.org/10.1038/nbt1210-1248

[52] Speicher, M.R. (1995) Microsatellite Instability in Human Cancer. Oncology Research, 7, 267-275.

[53] Sigrist, C.J., de Castro, E., Cerutti, L., Cuche, B.A., Hulo, N., Bridge, A., Bougueleret, L. and Xenarios, I. (2013) New and Continuing Developments at PROSITE. Nucleic Acids Research, 41, D344-D347. http://dx.doi.org/10.1093/nar/gks1067

[54] Mukherjee, J.J. and Dekker, E.E. (1990) 2-amino-3-Ketobutyrate CoA Ligase of Escherichia coli: Stoichiometry of Pyridoxal Phosphate Binding and Location of the Pyridoxyllysine Peptide in the Primary Structure of the Enzyme. Biochimica et Biophysica Acta, 1037, 24-29. http://dx.doi.org/10.1016/0167-4838(90)90097-Y

[55] Yasuda, S., Nishijima, M. and Hanada, K. (2003) Localization, Topology and Function of the LCB1 Subunit of Serine Palmitoyltransferase in Mammalian Cells. Journal of Biological Chemistry, 278, 4176-4183. http://dx.doi.org/10.1074/jbc.M209602200

[56] Batada, N.N., Urrutia, A.O. and Hurst, L.D. (2007) Chromatin Remodelling Is a Major Source of Coexpression of Linked Genes in Yeast. Trends in Genetics, 23, 480-484. http://dx.doi.org/10.1016/j.tig.2007.08.003

[57] Xu, C., Bailly-Maitre, B. and Reed, J.C. (2005) Endoplasmic Reticulum Stress: Cell Life and Death Decisions. Journal of Clinical Investigation, 115, 2656-2664. http://dx.doi.org/10.1172/JCI26373

[58] Moenner, M., Pluquet, O., Bouchecareilh, M. and Chevet, E. (2007) Integrated Endoplasmic Reticulum Stress Responses in Cancer. Cancer Research, 67, 10631-10634. http://dx.doi.org/10.1158/0008-5472.CAN-07-1705

[59] Kaklamani, V.G. and Pasche, B. (2004) Role of TGF- $\beta$ in Cancer and the Potential for Therapy and Prevention. Expert Review of Anticancer Therapy, 4, 649-661. http://dx.doi.org/10.1586/14737140.4.4.649

[60] Magrassi, L., Marziliano, N., Inzani, F., Cassini, P., Chiaranda, I., Skrap, M., Pizzolito, S., Arienta, C. and Arbustini, E. (2010) EDG3 and SHC3 on Chromosome 9q22 Are Co-Amplified in Human Ependymomas. Cancer Letters, 290, 36-42. http://dx.doi.org/10.1016/j.canlet.2009.08.023

[61] Contos, J.J., Ishii, I. and Chun, J. (2000) Lysophosphatidic Acid Receptors. Molecular Pharmacology, 58, 1188-1196.

[62] Hecht, J.H., Weiner, J.A., Post, S.R. and Chun, J. (1996) Ventricular Zone Gene-1 (vzg-1) Encodes a Lysophosphatidic Acid Receptor Expressed in Neurogenic Regions of the Developing Cerebral Cortex. Journal of Cell Biology, 135, 1071-1083. http://dx.doi.org/10.1083/jcb.135.4.1071

[63] Chun, J., Hla, T., Lynch, K.R., Spiegel, S. and Moolenaar, W.H. (2010) International Union of Basic and Clinical Pharmacology. LXXVIII. Lysophospholipid Receptor Nomenclature. Pharmacological Reviews, 62, 579-587. http://dx.doi.org/10.1124/pr.110.003111

[64] Blaho, V.A. and Hla, T. (2011) Regulation of Mammalian Physiology, Development, and Disease by the Sphingosine 1-Phosphate and Lysophosphatidic Acid Receptors. Chemical Reviews, 111, 6299-6320. http://dx.doi.org/10.1021/cr200273u

[65] Fei, D.L., Sanchez-Mejias, A., Wang, Z., Flaveny, C., Long, J., Singh, S., et al. (2012) Hedgehog Signaling Regulates Bladder Cancer Growth and Tumorigenicity. Cancer Research, 72, 4449-4458. http://dx.doi.org/10.1158/0008-5472.CAN-11-4123

[66] Thornton, M., Aslam, M.A., Tweedle, E.M., Ang, C., Campbell, F., Jackson, R., Costello, E., Rooney, P.S., Vlatković, N. and Boyd, M.T. (2013) The Unfolded Protein Response Regulator GRP78 Is a Novel Predictive Biomarker in Colorectal Cancer. International Journal of Cancer, 133, 1408-1418. http://dx.doi.org/10.1002/ijc.28137

[67] Albano, F., Zagaria, A., Anelli, L., Coccaro, N., Impera, L., Minervini, C.F., et al. (2013) Gene Expression Profiling of Chronic Myeloid Leukemia with Variant t(9;22) Reveals a Different Signature from Cases with Classic Translocation. Molecular Cancer, 12, 36. http://dx.doi.org/10.1186/1476-4598-12-36

[68] Qiu, Z., Cang, Y. and Goff, S.P. (2010) c-Abl Tyrosine Kinase Regulates Cardiac Growth and Development. Proceedings of the National Academy of Sciences of the United States of America, 107, 1136-1141. http://dx.doi.org/10.1073/pnas.0913131107

[69] Taouji, S., Higa, A., Delom, F., Palcy, S., Mahon, F.X., Pasquet, J.M., Bossé, R., Ségui, B. and Chevet, E. (2013) Phosphorylation of Serine Palmitoyltransferase Long Chain-1 (SPTLC1) on Tyrosine 164 Inhibits Its Activity and Promotes Cell Survival. Journal of Biological Chemistry, 288, 17190-17201. http://dx.doi.org/10.1074/jbc.M112.409185

[70] Rangé, H., Poitou, C., Boillot, A., Ciangura, C., Katsahian, S., Lacorte, J.M., Czernichow, S., Meilhac, O., Bouchard, P. and Chaussain, C. (2013) Orosomucoid, a New Biomarker in the Association between Obesity and Periodontitis. PLoS ONE, 8, Article ID: e57645. http://dx.doi.org/10.1371/journal.pone.0057645

[71] Breslow, D.K., Collins, S.R., Bodenmiller, B., Aebersold, R., Simons, K., Shevchenko, A., Ejsing, C.S. and Weissman, J.S. (2010) Orm Family Proteins Mediate Sphingolipid Homeostasis. Nature, 463, 1048-1053. http://dx.doi.org/10.1038/nature08787 
Scientific Research Publishing (SCIRP) is one of the largest Open Access journal publishers. It is currently publishing more than 200 open access, online, peer-reviewed journals covering a wide range of academic disciplines. SCIRP serves the worldwide academic communities and contributes to the progress and application of science with its publication.

Other selected journals from SCIRP are listed as below. Submit your manuscript to us via either submit@scirp.org or Online Submission Portal.
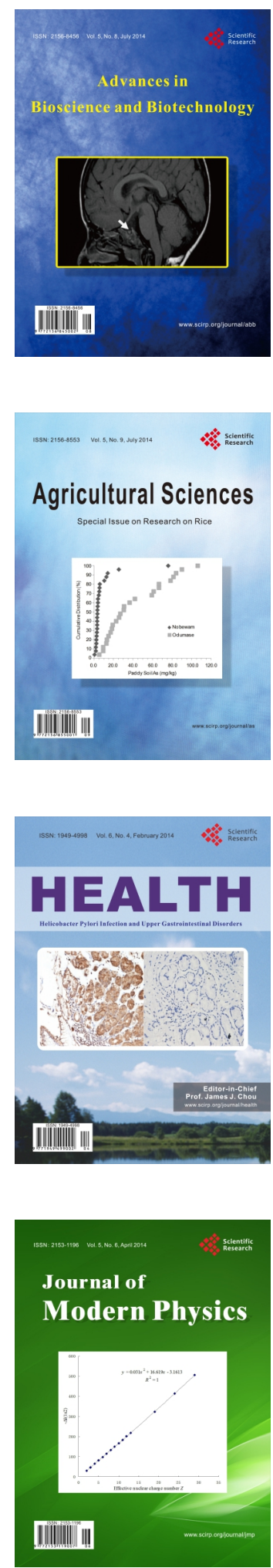
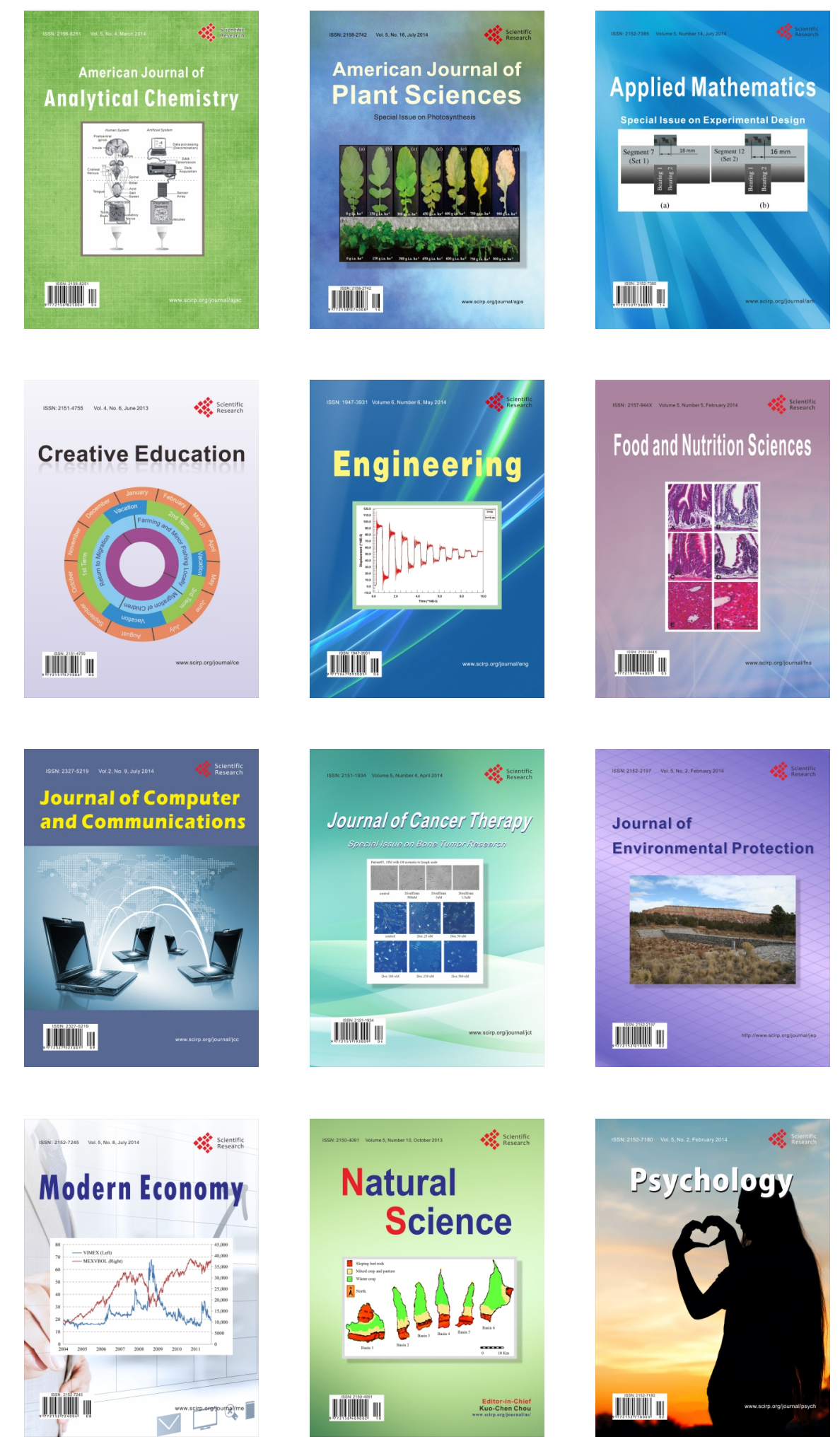